\title{
Estudo microscópico da interface implante-osso vertebral e sua relação com o modo de preparo do orifício piloto
} Microscopical study of the bone screw interface and its correlation with the pilot hole preparation

\author{
Estudio microscópico de la interface implante hueso vertebral y su \\ relación con el modo de preparación del orificio piloto
}

\author{
José Roberto Benites Vendrame' \\ Sérgio Brito Garcia ${ }^{2}$ \\ José Antonio Thomazini ${ }^{3}$ \\ Michel Carrijo Lutfala ${ }^{4}$ \\ Helton LA Defino ${ }^{5}$
}

\section{RESUMO}

Objetivo: estudar as alterações do tecido ósseo da interface entre o implante e o osso da vértebra submetido ao preparo do orifício piloto por meio de sonda, broca e broca seguida de macheamento. Métodos: foram utilizadas três vértebras lombares (12-L3-L4) de cadáveres humanos adultos do sexo masculino. No interior dos pedículos vertebrais, foram inseridos parafusos de $6 \mathrm{~mm}$ de diâmetro externo do sistema USIS de fixação vertebral. O preparo do orifício piloto para a inserção dos parafusos nos pedículos vertebrais foi realizado por meio de sonda, broca ou broca seguida de macheamento. As vértebras foram preparadas para o estudo em microscopia de luz e foi avaliado o coeficiente de fragmentação por meio da relação entre a porcentagem da área ocupada por tecido ósseo na região próxima do implante

\begin{abstract}
Objective: to access microscopically bone tissue changes between vertebral bone and implant interface, whose pilot hole was prepared using probe, drill and drill followed by tapping. Methods: the vertebral pedicles of three segments (L2-L3-L4) of human adult cadaver lumbar spine were instrumented with $6 \mathrm{~mm}$ USIS pedicle screw. The pilot holes for screw insertion into pedicles were prepared using probe, drill and drill followed by tapping. The vertebrae were prepared to histological study on light microscopy and the fragmentation index assessed by percentage relation between bone tissue close to the implant and normal bone. Results: the fragmentation index of pilot holes prepared with probes was statistically lower than those prepared with drill and drill followed by tapping.
\end{abstract}

\section{RESUMEN}

Objetivo: estudiar las alteraciones del tejido óseo de la interfase entre el implante y el hueso de la vértebra, sometido al preparo del orificio piloto por medio de sonda, broca y broca seguida de aplastamiento. Métodos: fueron utilizadas tres vértebras lumbares (L2L3-L4) de cadáveres humanos adultos del sexo masculino. En el interior de los pediculos vertebrales fueron insertados tornillos de $6 \mathrm{~mm}$ de diámetro externo del sistema USIS de fijación vertebral. El preparo del orificio piloto, para la inserción de los tornillos en los pedículos vertebrales, fue realizado por medio de sonda, broca o broca seguida de aplastamiento. Las vértebras fueron preparadas para el estudio en microscopio de luz y fue evaluado el coeficiente de fragmentación por medio de la relación entre el porcentaje del área ocupada por el tejido óseo en la región

\footnotetext{
Trabalho realizado no Laboratório de Bioengenharia do Departamento de Biomecânica, Medicina e Reabilitação do Aparelho Locomotor da Faculdade de Medicina de Ribeirão Preto da Universidade de São Paulo-USP, Ribeirão Preto (SP), Brasil.

'Pós-graduando do Departamento de Biomecânica, Medicina e Reabilitação do Aparelho Locomotor da Faculdade de Medicina de Ribeirão Preto da Universidade de São Paulo-USP, Ribeirão Preto (SP), Brasil.

${ }^{2}$ Professor-associado do Departamento de Patologia da Faculdade de Medicina de Ribeirão Preto da Universidade de São Paulo-USP, Ribeirão Preto (SP), Brasil. ${ }^{3}$ Professor Doutor do Departamento de Cirurgia e Anatomia da Faculdade de Medicina de Ribeirão Preto da Universidade de São Paulo-USP, Ribeirão Preto (SP), Brasil.

${ }^{4}$ Aluno de Iniciação Científica do Curso de Graduação da Faculdade de Medicina de Ribeirão Preto da Universidade de São Paulo-USP, Ribeirão Preto (SP), Brasil. ${ }^{5}$ Professor Titular do Departamento de Biomecânica, Medicina e Reabilitação do Aparelho Locomotor da Faculdade de Medicina de Ribeirão Preto da Universidade de São Paulo-USP, Ribeirão Preto (SP), Brasil.
} 
e no osso normal. Resultados: o coeficiente de fragmentação foi menor, com diferença estatística, no grupo do orifício piloto preparado com sonda em relação ao orifício piloto preparado com broca ou broca seguida de macheamento. Conclusão: o menor coeficiente de fragmentação observado com a utilização da sonda para a realização do orifício piloto indica a maior compactação do osso na interface entre o implante e o osso da vértebra.

Conclusion: the low fragmentation index observed that the use of probe to perform pilot hole promotes higher compaction of bone between the screw and vertebral bone interface.

KEYWORDS: Spine; Spinal fusion/ methods; Lumbar vertebrae/ surgery; Bone screws; Cadaver próxima del implante y en el hueso normal. Resultados: el coeficiente de fragmentación fue menor con diferencia estadística en el grupo del orificio piloto preparado con sonda, cuando comparado con el orificio piloto preparado con broca o broca seguida de aplastamiento. Conclusión: el menor coeficiente de fragmentación observado con la utilización de la sonda para la realización del orificio piloto indica la mayor compactación del hueso, en la interface entre el implante y el hueso de la vértebra.

\section{DESCRIPTORES: Columna} vertebral; Fusión vertebral/ métodos; Vértebras lumbares/ cirugía; Tornillos óseos; Cadáver

\section{INTRODUÇÃO}

A ancoragem no tecido ósseo dos parafusos do sistema de fixação vertebral representa a base mecânica de sustentação desses sistemas. A ancoragem dos parafusos e a sua resistência ao arrancamento dependem da densidade mineral do tecido ósseo, do diâmetro externo e do desenho das roscas do parafuso, e do orifício piloto ${ }^{1-3}$.

Dentre os parâmetros relacionados com o orifício piloto, o seu diâmetro e o modo de confecção podem influenciar na resistência ao arrancamento dos implantes. Observamos em ensaios mecânicos que a utilização de sondas para a confecção do orifício piloto aumenta a resistência ao arrancamento dos implantes ${ }^{4}$. Essa observação estaria relacionada à compactação do tecido ósseo nas paredes do orifício piloto com a utilização da sonda, enquanto a utilização da broca removeria o tecido ósseo ${ }^{5}$. O modo de preparo do orifício piloto influencia na resistência ao arrancamento dos implantes, e a utilização de sondas apresenta vantagens em relação às brocas ${ }^{2,4}$.

A realização deste estudo, delineado para observar e comparar as alterações microscópicas do tecido ósseo da interface entre o osso e o implante produzida pelo preparo do orifício piloto com broca ou sonda, tem a sua origem na observação dos resultados de ensaios mecânicos da influência do modo de preparo do orifício piloto ${ }^{4,6}$.

\section{MÉTODOS}

Foram utilizadas três vértebras lombares (L2-L3-L4) de cadáveres humanos adultos do sexo masculino, obtidos junto ao Serviço de Verificação de Óbitos do Departamento de Patologia da Faculdade de Medicina de Ribeirão Preto (USP). Os pedículos vertebrais foram perfurados para a confecção de orifícios pilotos sob visão direta, utilizandose as referências anatômicas clássicas (processo transverso e faceta articular superior) para a introdução dos parafusos pediculares do sistema de fixação vertebral. Os orifícios pilotos foram confeccionados por três diferentes modos: utilizando sonda de $3,5 \mathrm{~mm}$, broca de $3,5 \mathrm{~mm}$ e broca de 3,5 mm seguida de macheamento do orifício piloto.

Após o preparo do orifício piloto, os parafusos de $6 \mathrm{~mm}$ de diâmetro externo (3,5 $\mathrm{mm}$ de diâmetro interno) do sistema USIS de fixação vertebral (Ulrich) foram introduzidos no interior dos pedículos da vértebras. O modo de preparo do orifício piloto foi alternada e equitativamente distribuído nos pedículos das vértebras utilizadas no estudo.

As vértebras foram preparadas para o estudo com microscopia de luz, e os implantes, retirados para a descalcificação e processamento histológico de rotina do material a ser estudado. Foram realizados cortes histológicos transversais aos pedículos vertebrais para o estudo da interface entre o osso e o implante. Foram realizados cortes histológicos de $7 \mu$, que foram corados pela hematoxilina-eosina. Os cortes histológicos eram transversais ao pedículo vertebral, seriados ao longo do eixo do orifício piloto, com intervalos de dez cortes entre eles.

A metodologia estabelecida para o estudo do tecido ósseo da interface entre o implante e o tecido ósseo foi baseada no estudo histomorfométrico das trabéculas ósseas do pedículo vertebral, localizadas ao redor do trajeto do parafuso na interface entre o tecido ósseo e o implante. Foram estabelecidas e padronizadas duas áreas de avaliação: a área de fragmentação (Af) e a área de osso intacto (Ai).

A área de fragmentação (Af) correspondia à área de osso que circundava o orifício do parafuso a uma distância 
de até $1 \mathrm{~cm}$ do seu contorno interno. A área de osso intacto era formada pela região externa que circundava a área de fragmentação na parte externa (Figura 1). A porcentagem da área total ocupada pelo tecido ósseo foi medida na área de fragmentação (Af) e na área de osso intacto (Ai). $\mathrm{O}$ quociente dos valores da porcentagem de tecido osso na área de fragmentação (Af) e área de osso normal (Ai) foi denominado índice de fragmentação (Af/Ai) e utilizado para a avaliação da interface do tecido e implante cujos orifícios-piloto foram preparados por meio dos diferentes métodos. O baixo valor do índice de fragmentação indica maior compactação do tecido ósseo da interface entre o tecido ósseo da vértebra e o implante.
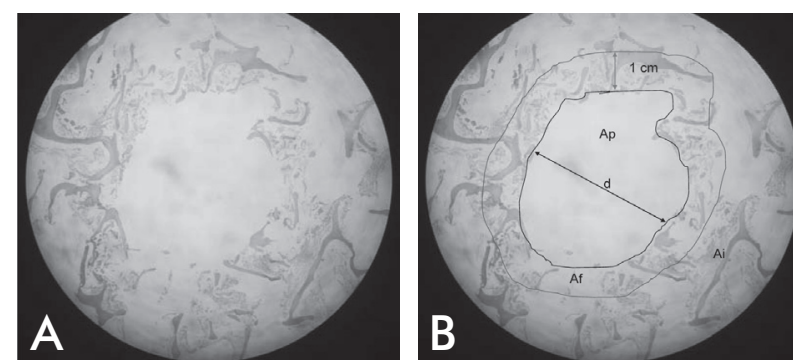

Figura 1

(A) Fotografia da lâmina histológica e (B) esquema ilustrando as áreas selecionadas para a medida da área do tecido ósseo. Observa-se a delimitação das áreas para o estudo. Área de fragmentação (Af), área de osso normal (Ai), e diâmetro do orifício piloto (d). Coloração HE 10x.
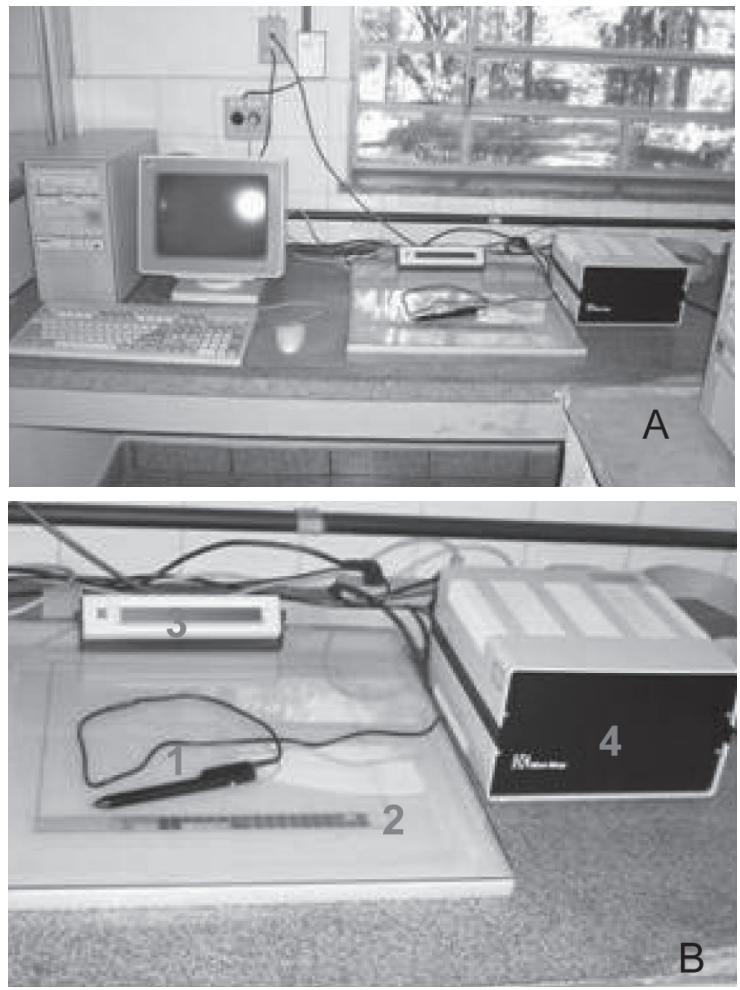

Figura 2

(A) Fotografia do aparelho Mini-Mop ${ }^{\circledast}$ acoplado ao computador e (B) o conjunto do 7 - sensor, 2- plataforma de captação, 3- leitor digital, 4- Mini-Mop ${ }^{\circledast}$.
Para a realização da medida da porcentagem de osso nas áreas mencionadas, as lâminas histológicas foram fotografadas com objetiva de $35 \mathrm{x}$ de aumento e impressas com aumento adicional de $15 \mathrm{x}$. As fotografias com aumento de 525x em relação ao corte histológico original foram utilizadas para a mensuração por meio do Mini-Mop ${ }^{\circledR}$ (Figura 2). A fotografia era fixada sobre uma prancha de captação do Mini-Mop e com o sensor de captação do aparelho era demarcada a margem de cada área a ser avaliada. Após a demarcação das áreas, avaliava-se a porcentagem do tecido ósseo (trabéculas ósseas) no interior da área demarcada, que era fornecida pelo Mini-Mop ${ }^{\circledR}$.

Foi utilizado teste estatístico para a comparação dos resultados relacionados dos três diferentes modos de preparo do orifício piloto. A análise estatística foi feita pelo teste não-paramétrico de Kruskal-Wallis, tendo sido adotado o nível de significância de $5 \%(\mathrm{p} \leq 0,05)$.

\section{RESULTADOS}

O preparo histológico do tecido ósseo sem o implante no seu interior produziu certa deformação no material e o orifício do parafuso não manteve a sua forma cilíndrica original. Foi possível observar a compactação do tecido ósseo ao redor das paredes do orifício, indicando a compactação do tecido ósseo ao redor da área de contacto com o implante. Foi constatado que, na periferia dos orifícios, região denominada área de fragmentação, a porcentagem de tecido ósseo era maior em relação à área de osso intacto em todos os métodos de perfuração utilizados (Figura 1).

A média dos valores do índice de fragmentação foi menor nos orifícios perfurados com sonda $(1,37 \pm 0,21)$ em relação aos orifícios perfurados com broca $(1,85 \pm 0,24)$ e broca seguida de macheamento $(2,06 \pm 0,84)$. Observou-se diferença estatística entre os valores do índice de fragmentação dos orifícios perfurados com sonda em comparação aos orifícios perfurados com broca e broca seguida de macheamento $(\mathrm{p}=0,02)$. Não foi observada diferença estatística entre os valores do índice de fragmentação dos orifícios perfurados com broca e os perfurados com broca seguida do macheamento (Figura 3).

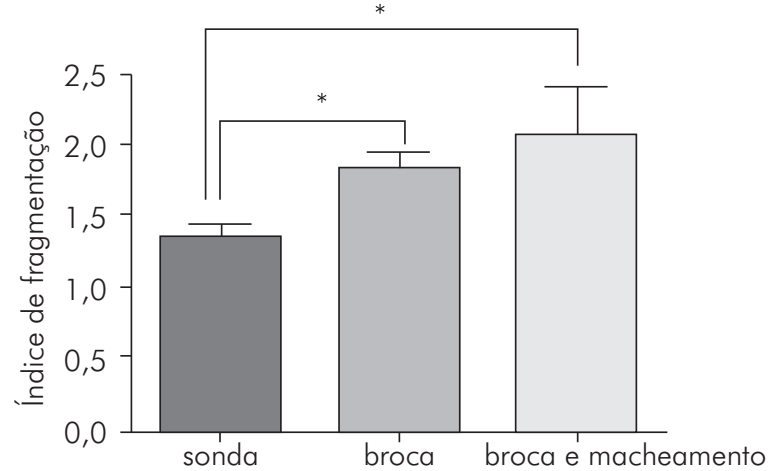

Figura 3

Gráfico ilustrando a comparação da média dos valores do índice de fragmentação nos diferentes modos de preparo do orifício piloto. O menor valor do índice de fragmentação indica maior compactação do tecido ósseo. $\mathrm{O}$ asterisco indica a diferença estatística entre os grupos. 


\section{DISCUSSÃO}

Os resultados observados nos estudos biomecânicos acerca da importância do modo de preparo do orifício piloto na resistência ao arrancamento dos implantes do sistema de fixação vertebral ${ }^{4,6}$ motivaram o estudo das alterações microscópicas da interface entre o implante e o tecido ósseo da vértebra. A realização do estudo partiu da hipótese de que as alterações microscópicas do tecido ósseo da interface entre o osso e o implante forneceriam subsídios necessários para a explicação dos resultados observados nos ensaios mecânicos.

O diâmetro do orifício piloto utilizado no estudo não era menor do que o diâmetro interno do parafuso, com a finalidade de eliminar a possível influência dessa variável, cuja participação na resistência ao arrancamento dos implantes do sistema de fixação vertebral tem sido observada em ensaios mecânicos ${ }^{6}$. A utilização de sonda e broca do mesmo diâmetro do diâmetro interno do parafuso eliminou a possível ocorrência da compressão do osso ao redor do implante pela parte interna do parafuso durante a sua inserção. Desse modo, a compactação do tecido ósseo ao redor do trajeto do implante sofreu a influência apenas do modo de preparo do orifício piloto.

Devido às características mecânicas do osso esponjoso, que possui menor resistência em relação ao osso cortical, a compactação do osso adjacente ao orifício piloto aumentaria a densidade óssea ao redor do implante e a sua resistência ao arrancamento, hipótese confirmada pelos resultados das alterações microscópicas da parede do orifício piloto e interface entre o implante e o tecido ósseo.

A utilização da sonda provoca a compactação do tecido ósseo na parede do orifício piloto, enquanto a broca provoca a sua remoção ${ }^{2,5}$. A impactação do osso nas paredes do orifício piloto tem sido apontada como fator que causaria aumento da resistência dos implantes ao arrancamento, e o macheamento do orifício piloto reduziria essa resistência, devido à lesão e destruição das trabéculas do osso esponjoso ${ }^{7-9}$. As perfurações com a broca provocam microfraturas, ao contrário do que ocorre com a utilização da sonda, na qual o osso esponjoso é compactado ao redor das paredes do orifício piloto. Se o macheamento produz redução da resistência ao arrancamento no osso esponjoso, efeitos similares podem ser produzidos com a perfuração do orifício piloto por meio da broca ${ }^{2-7}$. Os resultados observados neste estudo corroboram essa hipótese. No entanto, deve ser salientado que as alterações do tecido ósseo foram avaliadas na fase aguda, e estudos complementares que avaliem o comportamento do tecido ósseo da interface com o implante em períodos de maior seguimento para a observação das reações biológicas e de remodelação do tecido ósseo são necessários.

Embora tenhamos observado a influência do modo de preparo do orifício piloto, concordando com outros relatos $^{8}$, o mesmo fenômeno não pôde ser confirmado por outros autores ${ }^{3,9}$. O efeito do preparo do orifício piloto com sonda foi também observado experimentalmente no preparo da mandíbula para a colocação de implantes dentários ${ }^{10}$.

A densidade mineral óssea tem sido apontada como a responsável pela discordância dos resultados dos estudos que compararam a confecção do orifício piloto com sonda ou broca. A utilização de sonda nos ossos de alta densidade promoveram o aumento da resistência ao arrancamento, enquanto nos ossos com menos densidade mineral óssea esse efeito eram desprezível ${ }^{7,11}$. No entanto, essa observação não está de acordo com os nossos resultados, e tal variável poderá ser mais bem controlada em estudos futuros por meio da avaliação da densidade mineral do osso.

Embora os resultados dos ensaios mecânicos e do estudo microscópico in vitro na fase aguda da colocação dos implantes não expressem necessariamente a situação clínica real, experimentalmente foi observada a influência do modo de preparo do orifício piloto acompanhado de alterações microscópicas da interface do tecido ósseo, que fornecem subsídios para a compreensão dos resultados dos ensaios mecânicos.

\section{CONCLUSÃO}

O preparo do orifício piloto por meio de sondas provoca maior compactação do tecido ósseo ao redor do trajeto do orifício piloto e interface entre o implante e o osso da vértebra em comparação à utilização de broca ou broca seguida de macheamento.

\section{REFERÊNCIAS}

1. Ansell RH, Scales JT. A study of some factors which affect the strength of screws and their insertion and holding power in bone. J Biomech. 1968;1(4):279-302.

2. Carmouche JJ, Molinari RW, Gerlinger T, Devine J, Patience T. Effects of pilot hole preparation technique on pedicle screw fixation in different regions of the osteoporotic thoracic and lumbar spine. J Neurosurg Spine. 2005;3(5):364-70.
3. George DC, Krag MH, JohnsonCC, Van Hal ME, Haugh LD, Grobler LJ. Hole preparation techniques for transpedicle screws. Effect on pullout strength from human cadaveric vertebrae. Spine (Phila Pa 1976). 1991;16(2):181-4.

4. Defino HLA, Vendrame RB, Shimano AC, Kandziora F. Estudo da influência do modo de preparo do orifício piloto e do macheamento na ancoragem dos implantes vertebrais. Acta Ortop Bras. 2007;14(4):200-3.
5. Oktenoğlu BT, Ferrara LA, Andalkar N, Ozer AF, Sarioglu AC, Benzel EC. Effects of hole preparation on screw pullout resistance and insertional torque: a biomechanical study. J Neurosurg. 2001;94(1 Suppl):91-6.

6. Defino HLA, Wirch CRG, Shimano AC, Kandziora F. Influência do diâmetro do orificio piloto na resistência ao arrancamento dos parafusos do corpo vertebral. Acta Ortop Bras. 2007;15(2):76-9. 
7. Wittenberg RH, Shea M, Swartz DE, Lee KS, White AA 3rd, Hayes WC. Importance of bone mineral density in instrumented spine fusions. Spine. 1991;16(6):647-52.

8. Moran JM, Berg WS, Berry JL, Geiger JM, Steffee AD. Transpedicular screw fixation. J Orthop Res. 1989;7(1):107-14.

9. Daftari TK, Horton WC, Hutton WC. Correlations between screw hole preparation, torque of insertion, and pullout strength for spinal screws. J Spinal Disord. 1994;7(2):139-45.
10.Silva VC, Barbosa SV, Campos BP. Análise histológica do osso perimplantar após o preparo por brocas ou compactando por expansores ósseos. Rev Bras Implant. 2004;11(42):113-8.

11. Ryken TC, Clausen JD, Traynelis VC, Goel VK. Biomechanical analysis of bone mineral density, insertion technique, screw torque, and holding strength of anterior cervical plate screws. J Neurosurg. 1995;83(2):325-9.

\section{Correspondência}

Helton LA Defino

Avenida Bandeirantes, 3.900, $11^{\circ}$

andar - Monte Alegre

CEP: 11 4048-900 - Ribeirão Preto (SP), Brasil.

Tel./Fax: (16) 3633-0336 / 3602-2513

E-mail: hladefin@fmrp.usp.br 